\title{
USING MICROCOMPUTERS FOR CREATING VIRTUAL EDUCATIONAL MODELS OF TECHNICAL DEVICES USED IN INDUSTRY FOR THE SUPPORT OF TEACHING PROGRAMMABLE LOGICAL CONTROLLERS
}

\author{
Ondřej ZIMNÝ, Milan HEGER, Ivo ŠPIČKA, Tereza BARDAŠEVSKÁ, Lucie TREUTLEROVÁ \\ VSB - Technical University of Ostrava, Ostrava, Czech Republic, EU \\ ondrej.zimny@vsb.cz, milan.heger@vsb.cz, ivo.spicka@vsb.cz, tereza.bardasevska.st@vsb.cz, \\ lucie.treutlerova.st@vsb.cz
}

https://doi.org/10.37904/metal.2019.988

\begin{abstract}
Present fast development of automation technology and its optimal implementation in control of metallurgical processes requires trained specialists who will be able to manipulate with it and also design and set it up. That requires special practical training of university students. Metallurgical processes are typical for their complexity, large dimensions, high temperatures and high costs. This is the reason why it is not usually physically possible to implement these processes in the learning process in the form of physical models that would be used in teaching of their real-time control. In technical practise the PLC are used for control most often. PLC connection with models of technologies allows to increase quality of teaching in the field of technological process management. This article is mainly dedicated to the creation of microcomputer virtual models of important representatives of technological aggregates and their integration and communication with PLC. The advantage of virtual models is their easy hardware and software implementation, a variability, a small size, a low price and a sufficient model representation and visualisation of real technologies, aggregates and equipment of technological complexes. At the same time this ensures safety of students in the learning process. The article contains examples of virtual models of selected devices that are most often used in technical practise. The example of a virtual model is an assembly line transport and material sorting, level monitoring and regulation in tanks and containers, etc. These applications can be easily extended with other elements used in metallurgical industry. Whereas extension of quantity and types of virtual learning models just depends on the development of the appropriate software.
\end{abstract}

Keywords: Virtual model, mathematical model, PLC

\section{INTRODUCTION}

The success of teaching at universities is partly influenced by quantity and quality of practical exercises which can help students to be familiar with devices and technologies that they will encounter in technical practise after they finish school. The metalurgy contains many aggregates and technologies that differ from others. It is typical for them that they are very large, they use products of high weights, they use high temperature in manufacture and high safety requirements are placed on them. Visits of metallurgical and engineering facilities bring students a lot of interesting information and help them to get to know real technologies. However, the excursions provide just visual information with expert commentary. That is the reason why students can't actively participate in the management of monitored technologies. One solution is to acquire models of teached technologies for school lessons. In some cases it is also possible use physical models which are very effective in teaching [1], [2]. Despite this advantage they are not used quite often for teaching because they are very expensive and usually take up a lot of space to be authentic. Operations with using high temperatures important for many real processes can be realized only in the school laboratories of the specialized departments. The second option is to use special softwares for mathematical simulation of systems. They are mainly used for modelling and simulation of real controlled systems [3]. Often they have a theoretical significance and results in mathematical description and possible simulations. 
A combination of the properties of both attitudes can be the creation of virtual models with visualisation have many advantages when used in teaching. These models can be realised by programs on small which microcomputers where individual devices or technologies are visualized on the display. The virtual models can behave from the outside like a real object of observation by using inputs and outputs of microcomputer and a program implementing internal regularities of a real model. This allows an easy access and students can creatively get involved in active work with the model by designing and realisation of its control without presence of disproportionate requirements for space, availability, price and safety in the classroom.

\section{HARDWARE REALIZATION OF VIRTUAL MODELS}

Microcomputers, such as Arduino, are currently completely convenient for implementation of small virtual models of technological devices. They contain software with sufficient mathematical operations which are necessary for simulation of physical and other properties of real objects. They are equipped with many binary and analog inputs and outputs. In addition, they have the option of serial communication with devices that can suitably complete capabilities of a microcomputer.

In our case, the Arduino MEGA 2560 was used. This contains dozens of addressable pins connected to software-configurable binary inputs or outputs. Some of them can work directly in PWM mode like pseudoanalog outputs. The Arduino MEGA 2560 also obtains 16 analog inputs with a 10-bit resolution. They can be reconfigured to other binary inputs or outputs, if necessary. However, this type of Arduino doesn't have any classic analog output. That is the reason why we used two MCP4921 discrete D/A converters with a 12-bit resolution and $\mathrm{SPI}{ }^{\mathrm{TM}}$ interface. All outputs and inputs work with a maximum voltage of $+5 \mathrm{~V}$.

\section{VIRTUAL MODEL CONTROL}

In technical practice, PLC are used for the control process most often. In our case, for virtual model control we used PLC Compact Logix of Rockwell Automation containing digital output and input cards and an analog 8bite input/output card. These inputs and outputs are used in practice to obtain information from a real technological process and to control it. Therefore, the virtual model must provide and accept similar information as the real object. The connection of the control system with the virtual simulation model is shown in Figure 1.

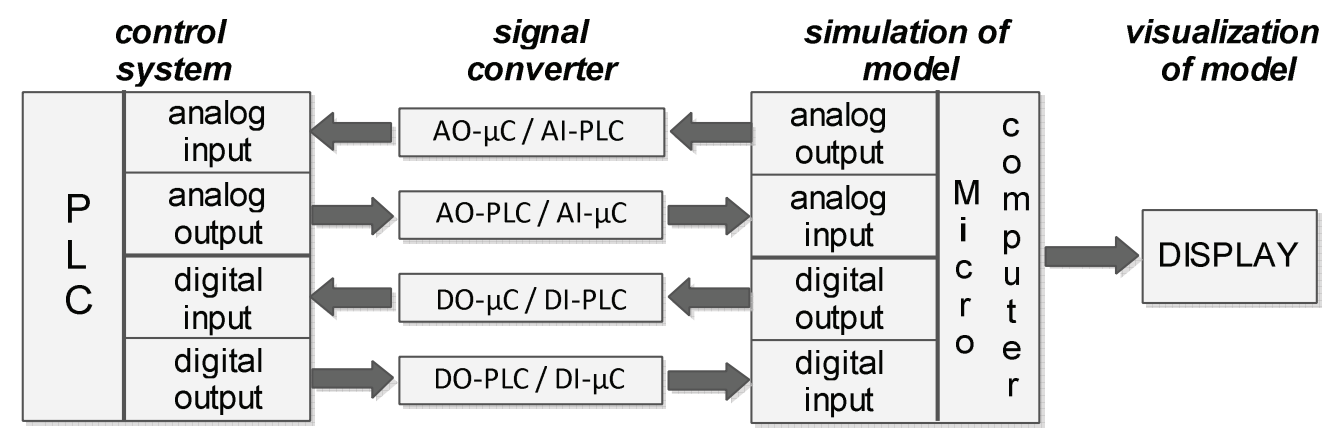

Figure 1 The connection of the control system with the virtual model

The control PLC using I/O cards is connected to I/O pins of the microcomputer via a signal converter. The graphic display, the appropriate software and the microcomputer realize a learning virtual model. The display shows a visualization of schematic representation of a real object and representation of monitored variables and the object behaviour.

Since the control system works with $0 \mathrm{~V}$ (False) and $24 \mathrm{~V}$ (True) binary signals, while the microcomputer virtual model works with $0 \mathrm{~V}$ (False) and $5 \mathrm{~V}$ (True) signals, similar to analog signals that use different voltage ranges, 
specifically PLC control system has range of $0-10 \mathrm{~V}$, while microcomputer virtual model uses 0-5 V range, there must be ensured an appropriate signal level conversion between the control system and the model as shown in Figure 2.

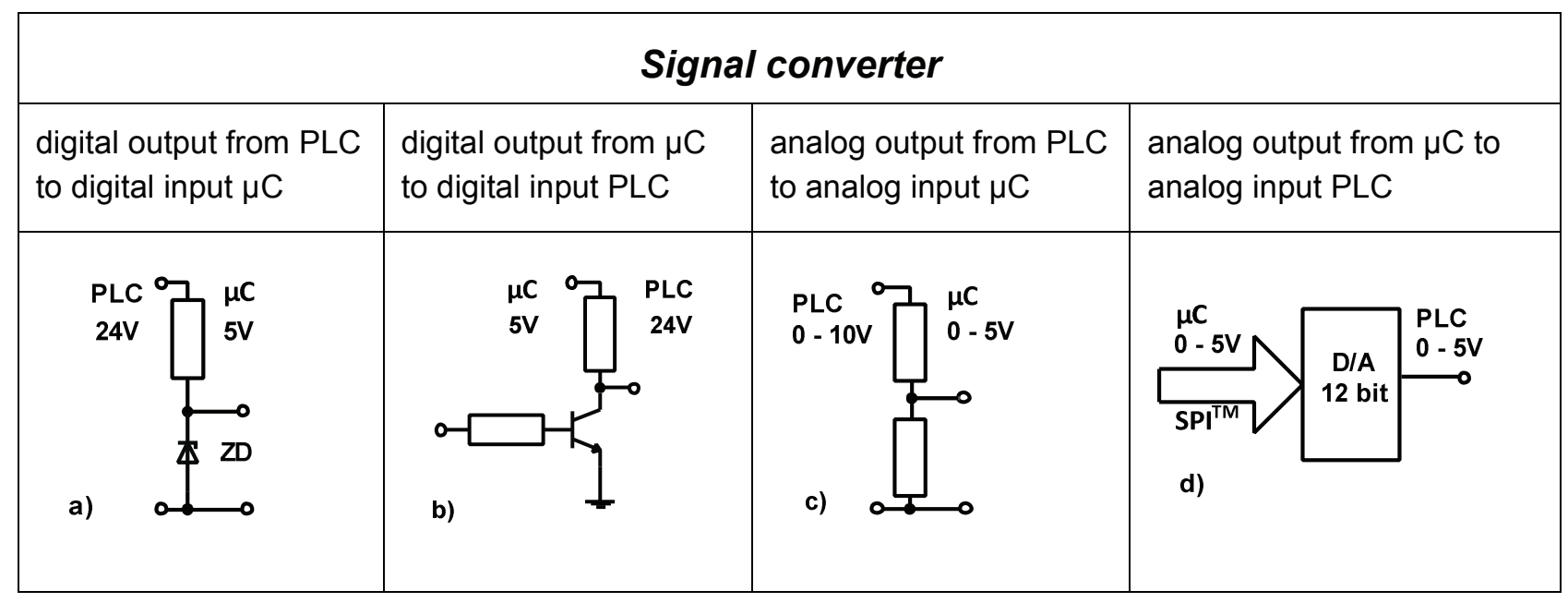

Figure 2 The signal conversion between the PLC and the $\mu \mathrm{C}$ model

Signal converter implementation:

a) To reduce the voltage from the PLC digital output to the digital input of the microcomputer, Zener diodes with stabilization voltage $+5 \mathrm{~V}$ were used.

b) To increase the voltage from the digital output of the microcomputer to the digital input on the PLC, transistor switches of common emitter configuration were used. That is why we get the negation of binary information at the PLC inputs coming from the microcomputer outputs.

c) To convert the analog signal from the PLC output to the microcomputer input the resistance dividers were used which were set to a 1:2 split ratio,

d) The microcomputer contains analog outputs, realized by PWM, which are unusable for this kind of application. That is why the classic D/A converters were used.

\section{SOFTWARE IMPLEMENTATION OF VIRTUAL MODELS}

Software realization of virtual models requires a virtual model behaviour as reliable as possible which involves three essential tasks:

1) To create very simple but accurate mathematical description of the behaviour of selected real objects, their software realization and their implementation into the microcomputer.

2) To create a suitable graphical interpretation for demonstrative model visualization of the real object, its immediate states and a transparent visualization of the monitored variables.

3) To create a system which provides periodic exchange of information between the PLC and the virtual model.

\section{MATHEMATICAL DESCRIPTIONS}

The complexity of mathematical description used in the model relies on the complexity of the real object. For the tuition there were selected simple systems with mathematical description in the form of Boolean functions. However, the set of used examples also includes dynamic systems described by differential equation [4]. 
It is usually sufficient to use a general linear differential equation with constant coefficients in the form:

$$
a_{n} y^{(n)}(t)+\cdots+a_{1} y^{\prime}(t)+a_{0} y(t)=b_{0} u(t)+b_{1} u^{\prime}(t)+\cdots+b_{m} u^{(m)}(t)
$$

where:

$$
\begin{aligned}
& a_{i} \text { - left hand side coefficients of differential equation } \\
& b_{j} \text { - right hand side coefficients of differential equation } \\
& u(t) \text { - input variable } \\
& y(t) \text { - output variable } \\
& n \text { - left hand side order of differential equation } \\
& m \text { - right hand side order of differential equation }
\end{aligned}
$$

or nonlinear equations too.

The mathematical description used in the virtual model of a free-run tank for education can be a good example:

$S \frac{d h(t)}{d t}=Q_{1}(t)-c \sqrt{h(t)}$

where:

$$
\begin{aligned}
& S \text { - a surface of cylindrical tank }\left(\mathrm{m}^{2}\right) \\
& h(t) \text { - water level }(\mathrm{m}) \\
& Q_{1}(t) \text { - tank inflow }\left(\mathrm{m}^{3} \mathrm{~s}^{-1}\right) \\
& c \text { - outflow constant }\left(\mathrm{m}^{5 / 2} \mathrm{~s}^{-1}\right)
\end{aligned}
$$

\section{VIZUALIZATION}

The design of models for simplicity is underway on PC in Delphi programming language. Then it is converted to the language which is used for programming microcomputer Arduino. Examples of other virtual models in the phase of design on PC are shown in Figure 3.
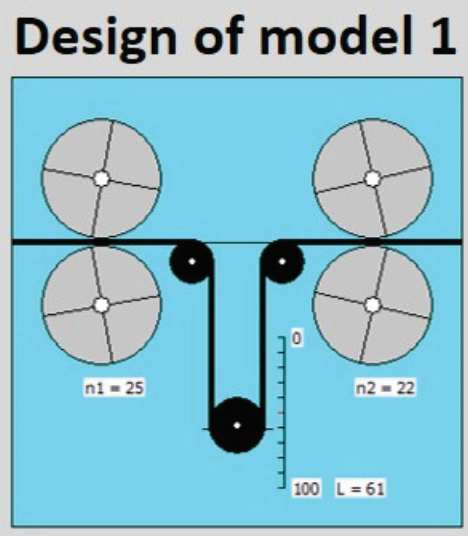

\section{Design of model 2}

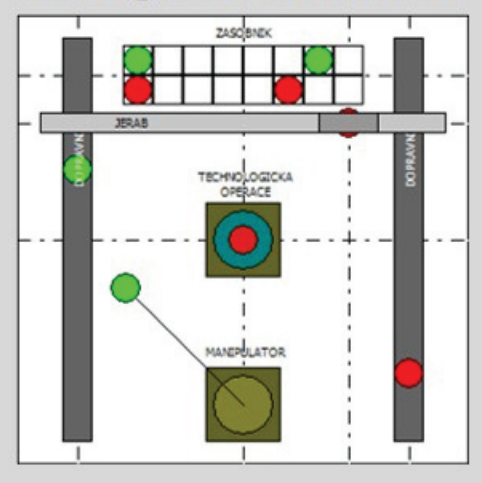

Figure 3 An example of virtual models design on PC.

Both the visualization and the mathematical descriptions and their link to display are simultaneously solved on a PC. 
The quality of the visualization depends on the quality of the display. In our case, we used a small, colour, graphic display with the resolution of $320 \times 470$ pixels that cause that details depiction or the scope of the visualization are partly limited. Examples of individual realizations are shown in Figure 4.

\section{Process visualization 1}

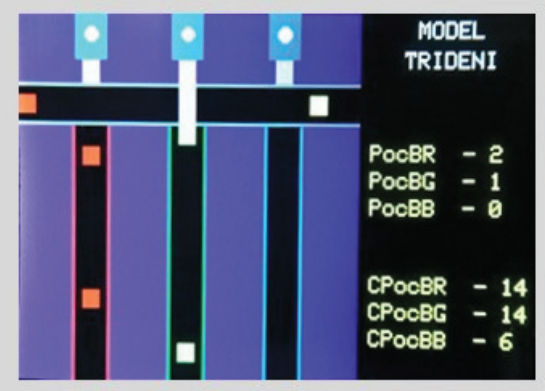

Process visualization 2

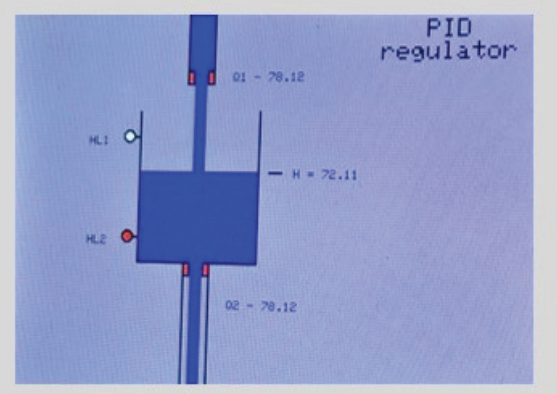

Figure 4 Demonstration of virtual models realized on the display of the microcomputer

There are representatives of virtual models of dynamic systems controlled by logical functions and by PID controller on the figure.

\section{PRINCIPLE OF COMMUNICATION BETWEEN A VIRTUAL EDUCATIONAL MODEL AND THE PLC}

The learning model must accurately imitate the real system with respect to provide and process information. If you look at the model from the point of view of the PLC, it represents a source of information which would be provided by sensors in real systems and it must process the information like if the PLC sent it to the actuators. The actual communication is seen in Figure $\mathbf{5}$.

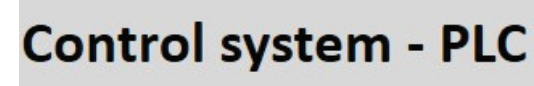

\section{Design of virtual model}

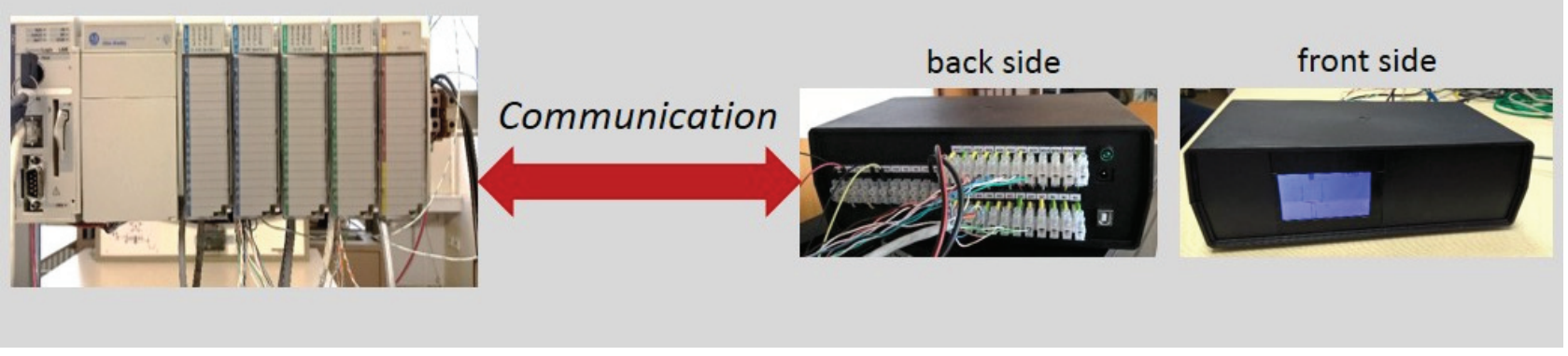

Figure 5 Hardware arrangement of communication between the PLC and the virtual model.

\section{CONCLUSION}

Constant requirements of students for a deeper connection between the theoretical part of education and the practice in the metallurgical industry led to the effort to create virtual models of real production equipments and production technologies in the school laboratories, so they provide a very authentic realization of the theoretical control projects of real metallurgical aggregates.

The created virtual educational models were realized on the basis of microcomputer Arduino MEGA 2560. The software allows an application of mathematical description of real objects with the visualization of their actual states and the information transfer between the model and the control system which is realized by the PLC. 
The models enable students not just to design and implement individual ways of managing simpler and more complex technologies by the PLC, but also to create their own virtual models by acquiring knowledge from subjects like Identification and Automatic or optimal control theory [5].

During the course it was verified that the models actually simulate real production devices which communicate with the control system via continuous and binary quantities as well as the real systems equipped with sensors that communicate with their actuators.

In addition, the devices are realized to make work safe, but at the same time the most accurate physical similarity with the real object must be kept. The universality of the device is also based on the fact that its selfcontrol can be easily realized at the lowest level by a microcomputer, but the control system can be a powerful $\mathrm{PC}$ or a control computer as well.

\section{ACKNOWLEDGEMENTS}

This paper has been elaborated in the framework of the project SP 2019/17 and project SP 2019/62.

\section{REFERENCES}

[1] SEIDL, D., KOŠTIAL, P., JANČíKOVÁ, Z., RUŽIAK, I., RUSNÁKOVÁ, S., FARKAŠOVÁ, M. Modal analysis Measurements versus FEM and artificial neural networks simulation, Communications in Computer and Information Science, Volume 188 CCIS, Issue PART 1, s. 170-175, ISSN 18650929, ISBN 978-364222388-4, 2011

[2] KOŠTIAL, P., ŠPIČKA, I., JANČíKOVÁ, Z., VALÍČEK, J., HARNIČÁROVÁ, M., HLINKA, J. On Experimental Thermal Analysis of Solid Materials. Measurement Science Review. 2014. vol. 14, no. 6, p. 317-322.

[3] LANDRYOVÁ, L., BABIUCH, M., Modeling Objects of Industrial Applications. Handbook of Research on Social Dimensions of Semantic Technologies and Web Services. - Chapter XXXVI, Information Science Reference, 2009, s. 743-759, ISBN 978-1-60566-651-8

[4] VÍTEČEK, Antonín a Miluše VÍTEČKOVÁ. Closed-loop control of mechatronic systems. Ed. 1st. Ostrava: VSB Technical University of Ostrava, 2013. ISBN 978-80-248-3149-7.

[5] VÍTEČKOVÁ, M., VÍTEČEK, A., Compensation tuning of analog and digital controllers for first order plus time delay plants.. Sborník vědeckých prací Vysoké školy báňské - Technické univerzity Ostrava. Řada strojní, Vysoká škola báňská - Technická univerzita Ostrava, 2011, s. 259-266, ISSN 1210-0471 